\title{
Single Convention on Narcotic Drugs
}

National Cancer Institute

\section{Source}

National Cancer Institute. Single Convention on Narcotic Drugs. NCI Thesaurus. Code

C21127.

The principal international treaty regulating availability of opioids. It classifies the opioids, and requires the registration of all handlers and the estimation of medical needs for opioids. It establishes rules concerning production, manufacture and distribution, and requires statistical reports. The Single Convention governs how opioids are shipped between countries, using a system of import and export approval. The treaty also defines to some extent the requirements for safe distribution within a country. 